\title{
Agrobacterium-mediated Genetic Transformation of Lentil (Lens culinaris Medik.) with Chitinase Gene followed by In vitro Flower and Pod Formation
}

\author{
Subroto K. Das', Kishwar Jahan Shethi, M. I. Hoque and R. H. Sarker* \\ Department of Botany, University of Dhaka, Dhaka-1000, Bangladesh
}

Key words: Lentil, Transformation, Chitinase, Selection, In vitro flower

\begin{abstract}
To investigate the integration of chitinase gene in lentil (Lens culinaris Medik.) namely, BARI masur-4 (BM-4), BARI masur-5 (BM-5) and BARI masur-6 (BM-6) through Agrobacterium-mediated genetic transformation was performed using Agrobacterium strain EHA 105 harboring bar (resistant to phosphinotrycin) and chitinase (gene of interest) gene. Selection of transformed shoots was carried out by gradually increasing the concentration of phosphinotrycin (PPT) up to $2.0 \mathrm{mg} /$. Transgenic lentil shoots were produced with an overall frequency of 0.36 in case of BM- 4 and BM- 6 and 0.34 in case of BM-5, respectively. Most of the selected shoots developed in vitro flowers and pods following their sub-culture on half strength of MS supplemented with $20 \mathrm{mg} / \mathrm{IBA}, 0.5$ $\mathrm{mg} /$ NAA with $50 \mathrm{mg} /$ ticarcillin. Seedlings germinated from the seeds were successfully transferred to soil for the development of further progeny. Stable integration of target gene was confirmed through PCR analysis.
\end{abstract}

\section{Introduction}

Lentil (Lens culinaris Medik.) may have been one of the first agricultural crops grown more than 8,500 years ago. It is the only one legume where most of the species convert nitrogen from the atmosphere into nitrogen in the nodules on the plant roots. This important grain legume gained worldwide economic importance as a source of protein for human and animal nutrition. The importance of lentil lies in the fact that it is a major source of good quality protein in the common diet as the protein content can reach up to $24-30 \%$. Hundred grams of lentil has as much protein as 130 grams of meat in addition to beneficial dietary fibers. Besides, it is high in amino acids, carbohydrate, calories,

\footnotetext{
*Author for correspondence: <rhsarker2000@yahoo.co.uk>. 1Department of Botany, University of Barishal, Barishal-8200, Bangladesh.
}

DOI: https://doi.org/10.3329/ptcb.v29i1.41982 
fiber, vitamin A, calcium, starch, iron, phosphorous, copper and manganese (Williams et al. 1994). As a good source of cholesterol-lowering fiber, not only do lentils help lower cholesterol, they are of special benefit in managing blood-sugar disorders since their high fiber content prevents blood sugar levels from rising rapidly after a meal. Lentil's nutrition is a contribution to heart health that lies not just in their fiber, but in the significant amounts of foliate and magnesium. These characteristics make lentil an important crop and ensured its survival to the present day. People like eating lentil as evidenced by production increases from about 1 million tons in 1960 to over 4 million tons to date.

From the above discussion, it is evident that the demand for this crop has been steadily increasing in the Indian subcontinent for its nutritional value, cooking quality and easy digestibility. On a global scale, lentil consumption is rising at a rate more than twice that of the human population growth. It is expected that by 2030, world lentil consumption will be double.

Although lentil is considered as an important pulse crop for many parts of the world but its production in most countries is usually characterized by low yield potential. Several factors are supposed to be responsible for the lower production of this important crop which includes susceptibility to disease, pests, fungi, massive flower drop, post harvest loss, and management problem (Erskine 1984). Among these constraints fungal diseases cause the maximum damage. A total of 17 diseases of lentil have been identified in Bangladesh (Bakr 1994) of which fungal diseases are most devastating and may occur at various stages of development.

In the past, several attempts have been made to develop disease resistant as well as high yielding varieties of lentil through distant hybridization and mutation breeding. But the progress of improvement through conventional breeding is hampered due to lack of genetic variability which caused by a predominantly high degree of self pollination and absence of resistance gene/s of interest in the existing lentil germplasm. Moreover, crossing in lentil is tedious because of small size of flowers.

It is therefore, imperative to look for some other methods to introduce genetic variability in lentil. Among the different approaches, Agrobacterium-mediated genetic transformation has been considered as the most common and successful method used in production of transgenic lentil plants (Warkentin and McHughen 1991, 1992, 1993, Barton et al. 1997, Halbach et al. 1998, Gulati and McHughen 2003, Sarker et al. 2003, Celikkol et al. 2009, Das et al. 2012). Most of these studies were carried out mainly for the development of a protocol for Agrobacterium-mediated genetic transformation of different varieties of lentil, very limited information is available regarding the genetic transformation using fungal resistance gene in grain legumes.

In these backgrounds the purpose of the study is to integrate chitinase gene in microsperma variety of lentil through Agrobacterium-mediated genetic transformation. 
Chitinase genes are potentially most promises as the enzymes degrade the substance chitin found in fungal cell wall and they showed activity against a wide range of fungus (Lorito 1998). Hence, genetic engineering of plants with chitinase gene is attractive for fungal disease control mechanism.

\section{Materials and Methods}

Cotyledon attached decapitated embryo (CADE) explants of three microsperma varieties of lentil (BM-4, BM-5 and BM-6) cultivated in Bangladesh were used as the plant materials for this investigation. Seeds of these three varieties of lentil were collected from Bangladesh Agricultural Research Institute (BARI), Joydebpur, Gazipur and maintained in the Plant Breeding and Biotechnology Laboratory of the Department of Botany, University of Dhaka.

Seeds of lentil were surface sterilized by rinsing them with 70\% alcohol for $1 \mathrm{~min}$ and then kept in $2 \%$ sodium hypo chloride supplemented with one drop of tween 20 for 10 min, which was followed by thorough washing with sterile distilled water for 3 - 4 times. The seeds were then soaked overnight in sterile distilled water.

For the preparation of CADE explants, overnight soaked seeds were taken in a sterilized petri dish, the seed coats are removed, seeds were split open and removing the root and shoot tips from embryo. Then one part of cotyledon containing decapitated embryo was used as explants. Explants were then placed on MS medium supplemented with $0.5 \mathrm{mg} / \mathrm{BAP}+0.5 \mathrm{mg} / \mathrm{Kn}+0.1 \mathrm{mg} / \mathrm{GA} 3+5.5 \mathrm{mg} /$ tyrosin for regeneration of shoots. The cultures were maintained under fluorescent illumination on a $16 \mathrm{~h}$ photoperiod at $25 \pm 2^{\circ} \mathrm{C}$.

The hypervirulent Agrobacterium tumefaciens strain EHA105 (Hood et al. 1993) harboring the pGreenII 0229 derivative binary plasmid containing a bar gene and the pSoup helper plasmid, (pGreen website: HYPERLIK "http://www.pgreen.ac.uk/" http:/wwww.pgreen.ac.uk), (Hellens et al. 2000) was used for transformation. This binary vector contains 'bar' gene (encoding phosphinothricin-acetyl transferase driven by NOS promoter and NOS terminator which conferring phosphinothricin resistance is present as selectable marker) within the right border (RB) and 'chitinase' gene [isolated from Streptomyces olivaceoviridis (ATCC 11238). Chimeric constructs were developed by fusing the Arabidopsis thaliana leader peptide (NCBI, AY081519) to the chitinase gene behind the stilbene synthase promoter (pGIIvstN-Chitin) from grape (Wiese et al. 1994)] within left border (LB) region of the construct (Fig. 1).

For infection of explants, overnight grown Agrobacterium culture was centrifuged for $10 \mathrm{~min}$ at $5000 \mathrm{rpm}$ and the pellet was re-suspended in liquid MS (pH 5.8) to make the Agrobacterium suspension. This Agrobacterium suspension was used for infection and 
incubation. Prior to this Optical Density (OD) of the bacterial suspension was determined at $600 \mathrm{~nm}$ with the help of a spectrophotometer (Shimadzu, Japan).

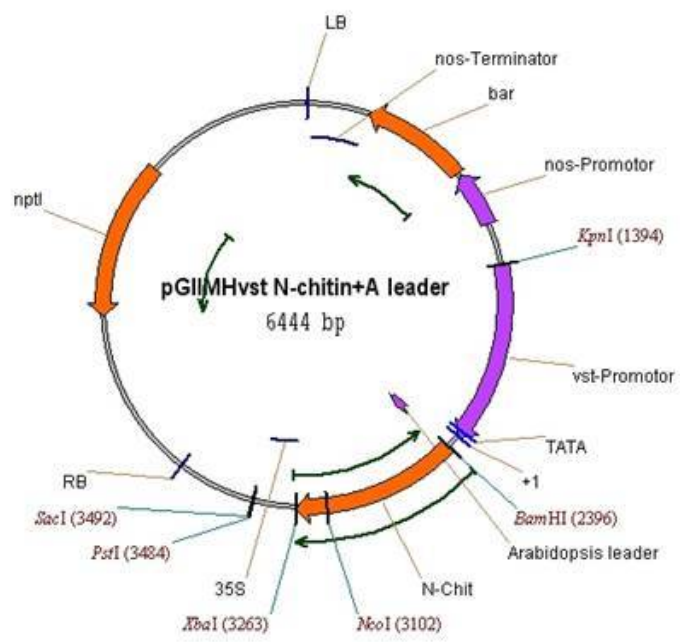

Fig. 1. Diagrammatic representation of Agrobacterium tumefaciens strain EHA 105 containing plasmid pSOUP-pGII-VST-N-Chit.

Following the infection and incubation, the explants were soaked in filter papers for a short period of time to remove excess bacterial suspension. All the explants were maintained in co-culture medium in dark condition. After 2 - 4 days the co-cultured explants were washed with distilled water for three-four times until no opaque suspension was seen, then washed for $15 \mathrm{~min}$ with distilled water containing $300 \mathrm{mg} /$ ticarcillin. The explants were then dried with a sterile Whatman filter paper and transferred to regeneration medium with $100 \mathrm{mg} /$ ticarcillin. After $7-10$ days, the regenerated shoots were sub-cultured in selection medium containing $0.5 \mathrm{mg} / \mathrm{ppt}$ and $100 \mathrm{mg} \lambda$ ticarcillin. Cultures were sub-cultured regularly at an interval of 12 - 15 days and the concentration of PPT was gradually increased up to $2.0 \mathrm{mg} \Lambda$. Shoots survived on selection medium were sub-cultured on half strength of MS containing $20 \mathrm{mg} \Lambda$ IBA and $0.5 \mathrm{mg} / \mathrm{NAA}$ subjected to in vitro flowering and seed formation.

The presence of the bar and chitinase genes in the lentil genomic DNA was analyzed by PCR. DNA was isolated from putatively transformants and non-transformed plant using the CTAB method (Doyle and Doyle 1990). For the detection of the bar coding sequence, DNA was subjected to PCR using the following primers and conditions: forward 5'- GAT TTC GGT GAC GGG CAG GA -3' and reverse 5'- TGC GGC TCG GTA CGG AAG TT - $3^{\prime}$. For the chitinase gene the primers were: forward 5'- GGT GAC ATC GTC CGC TAC AC -3' and reverse 5'- GGT GTT CCA GTA CCA CAG CG -3' (MGWBiotech, AG, Germany). All primers were used at a concentration of $100 \mathrm{pmol} / \mu \mathrm{l}$. The 
plasmid pBI121 isolated from Agrobacterium tumefaciens was used as the positive control. PCR reaction mix of $25 \mu \mathrm{l}$ contained $2.5 \mu \mathrm{l}$ of $10 \times \mathrm{PCR}$ buffer with $15 \mathrm{mM} \mathrm{MgCl} 2$ (Gene Craft, Germany), $1 \mu \mathrm{l}$ of $5 \mathrm{mM}$ of the dNTP mix, $1 \mu \mathrm{l}$ of Red Taq polymerase (Natutech, Germany), $1 \mu \mathrm{l}$ of each of the respective primers, and $1 \mu \mathrm{l}(50-80 \mathrm{ng} / \mu \mathrm{l})$ of the sample DNA and $17.5 \mu \mathrm{l}$ ultra pure water. For PCR amplification of bar and chitinase gene, DNA was denatured at $94^{\circ} \mathrm{C}$ for $5 \mathrm{~min}$ and then amplified in 35 cycles using $94^{\circ} \mathrm{C}$ for $1 \mathrm{~min}$, $59^{\circ} \mathrm{C}$ for $1 \mathrm{~min}$ (annealing) and $72^{\circ} \mathrm{C}$ for $1 \mathrm{~min}$ followed by $5 \mathrm{~min}$ at $72^{\circ} \mathrm{C}$. The amplified DNA was run on $1.0 \%$ agarose gel and stained with ethidium bromide $(0.05 \mu \mathrm{g} / \mathrm{ml})$.

\section{Results and Discussion}

Agrobacterium-mediated genetic transformation procedure is believed to be influenced by several factors (Mansur et al. 1993). Factors that influence successful transformation, such as type of Agrobacterium strain, genotype (host) compatibility and responsiveness of explants toward Agrobacterium infection, optical density (OD) of Agrobacterium suspensions, incubation and co-cultivation period were optimized in conducting transformation experiments.

For this purpose optical density (OD) was measured at $600 \mathrm{~nm}$ and bacterial suspension with optical density of $0.5,0.8,1.0$ and 1.2 having incubation period of 10, 20 and $30 \mathrm{~min}$ were used. It was observed that more than $20 \mathrm{~min}$ of incubation with optical density of 1.0 or above of bacterial suspension resulting overgrowth of bacteria in the cocultured plates and this kind of overgrowth hampered proper growth of the explants. Negligible overgrowth was observed when the explants where infected with the Agrobacterium suspension having an O.D of maximum 1.0 with incubation period of 20 min or less than this. Therefore, the optimum incubation period was found to be $20 \mathrm{~min}$ with OD of $0.8-1.0$.

Duration of co-cultivation was also played an important role to recover explants after transformation. Four different co-cultivation periods ranging from 2 - 5 days with OD of 0.8 and 1.0 were tried to find out the optimum co-culture period. It was observed that a co-cultivation for more than 3 days occasionally promoted overgrowth of bacteria and 5 days of co-cultivation period a remarkable overgrowth of bacteria was observed which covered the whole culture plate. As a result most of the explants in co-culture media suffered from poor health, became brown and failed to regenerate. Based on the above results it is suggested that, 3 days of co-cultivation period with OD of 1.0 is optimum for transformation.

In chickpea Krishnamurthy et al. (2000) incubated mature embryo explants for 20 min and then co-cultivated the explants for 3 days and were able to obtain transgenic plants. Warkentin and McHugen (1992) reported that, they were able to observe transient GUS expression from inoculating lentil epicotyl explants incubated only for 10 - $15 \mathrm{~min}$, but they did not mention the information on transformation frequency. 
Selection of transformed cells is an important component of any plant transformation system. In absence of proper selection system one would face with the option of screening every shoot regenerated from the infected explants.

In this experiment PPT was used as selective agent as the strain contained bar gene which is resistant to PPT. To find out the appropriate concentration of selection agent different concentrations (0.5-2.0 mg $\Lambda$ ) of PPT were used. From this experiment it was revealed that with the increase of PPT concentration the percentage of survived shoots were found to decrease and in $2.0 \mathrm{mg} / \mathrm{PPT}$ the explants failed to survive within 10 days of inoculation (Fig. 2A). Therefore, this concentration (2.0 $\mathrm{mg} / \mathrm{PPT})$ was used for selection of transformed shoots.
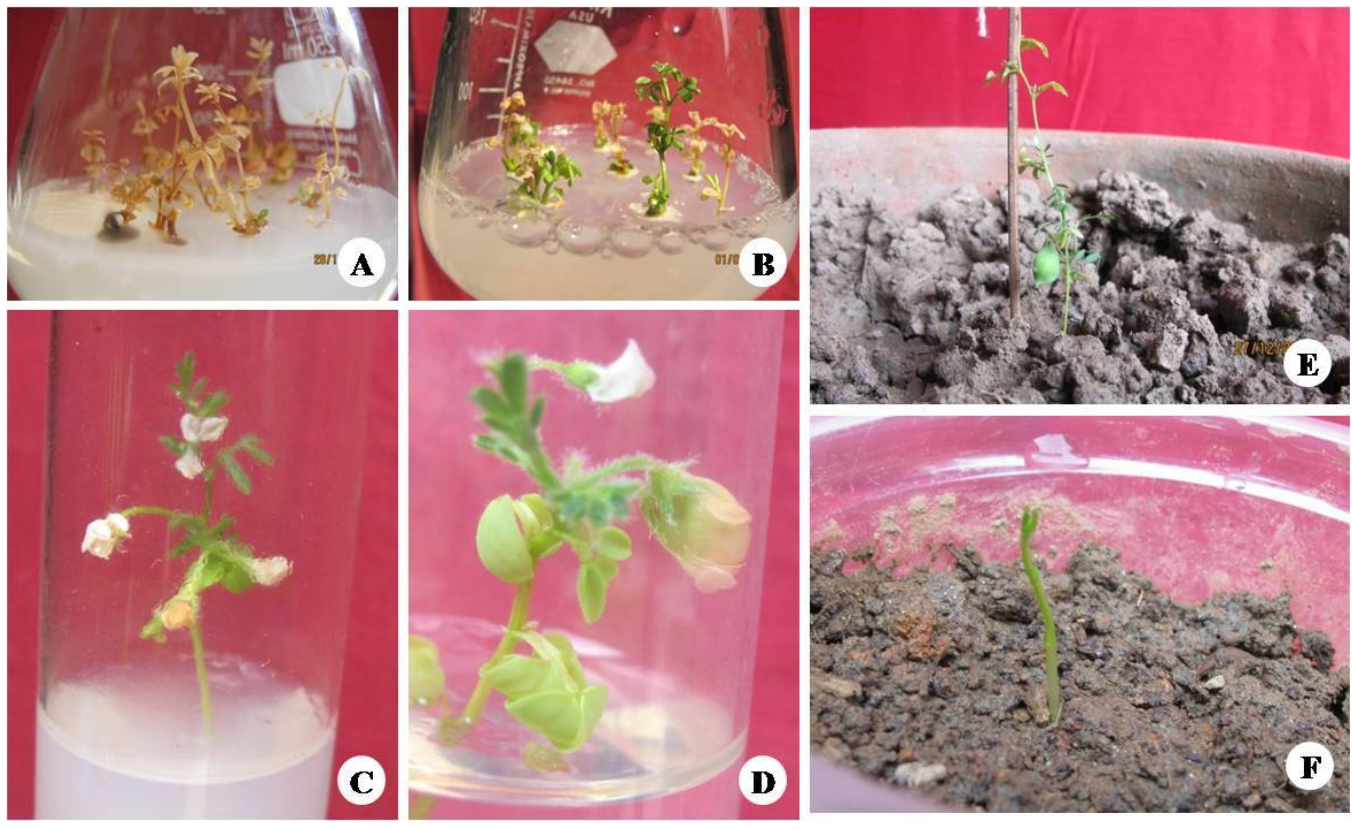

Fig. 2. Selection and development of transformed lentil progenies. A. Control shoots of BM-5 regenrated from CADE explants showing necrosis (leading to death) following selection pressure of $2.0 \mathrm{mg} / \mathrm{A}$ phosphinothricin (PPT). B. Putatively transformed shoots of BM-6 (green) survived on medium containing $2.0 \mathrm{mg} /$ PPT. C. In vitro flower developed from shoots survived on selection medium. D. Same as Fig. C showing fully developed pod. E. T1 plants growing in pot showing the formation of pod. F. Germination and growing of $\mathrm{T}_{2}$ plants in soil.

During the selection of transformed shoots, following co-cultivation for 3 days explants were washed with $300 \mathrm{mg} /$ ticarcillin for $10 \mathrm{~min}$ and then transferred to regeneration media without any selection pressure for a short period of time. When the regenerating shoots attend to $3-4 \mathrm{~cm}$ long they were sub-cultured on the fresh regeneration media with $1.0 \mathrm{mg} /$ PPT (selection media). After 14 days of first selection pressure only green and healthy shoots were sub-cultured on fresh regeneration medium 
with $1.5 \mathrm{mg} /$ PPT. PPT concentration was raised up to $2.0 \mathrm{mg} /$ in the third subculture and then again in $2.0 \mathrm{mg} /$ in the fourth sub-cultures. During each sub-culture, deep brown dead shoots were discarded and only green shoots were sub-cultured on fresh medium containing the next higher concentration of PPT.

Finally shoots that survived on regeneration medium containing $2.0 \mathrm{mg} \Lambda \mathrm{PPT}$ were considered as transformed shoots (Fig. 2B). A total of 7 shoots out of approximately 2780 infected explants in case of BM - 4, 7 out of 2040 in case of BM - 5 and 12 out of 3330 in case of BM - 6 survived on $2.0 \mathrm{mg} / \mathrm{PPT}$. Therefore, the frequency of recovery of putative transformed shoots was about $0.36 \%$ in case of BM- $4,0.34 \%$ in case of BM-5 and $0.36 \%$ in case of BM-6 (Table 1). In each set of experiments, regenerated control explants were also maintained to perform various comparative studies between transformed and non transformed shoots.

Table 1. Effect of PPT concentration on transformation efficiency of lentil.

\begin{tabular}{lccccccccc}
\hline Variety & $\begin{array}{c}\text { Total no. of } \\
\text { explants } \\
\text { infected }\end{array}$ & $\begin{array}{c}\text { No. of explants } \\
\text { transferred to } \\
\text { regeneration media }\end{array}$ & $\begin{array}{c}\text { No. of shoot } \\
\text { survived }(\mathrm{mg} / \text { PPT) }\end{array}$ & $\begin{array}{c}\text { \% of } \\
\text { survived } \\
\text { shoots }\end{array}$ & $\begin{array}{c}\text { No. of shoots } \\
\text { subjected for } \\
\text { PCR analysis }\end{array}$ & $\begin{array}{c}\text { No. of } \\
\text { PCR +ve } \\
\text { shoots }\end{array}$ \\
\hline BM - 4 & 2780 & 2606 & 214 & 30 & 10 & 0.36 & 7 & 1 \\
BM - 5 & 2040 & 1980 & 123 & 21 & 7 & 0.34 & 7 & 1 \\
BM - 6 & 3330 & 3040 & 243 & 33 & 12 & 0.36 & 12 & 6 \\
\hline
\end{tabular}

It may be mentioned here that till now the overall transformation efficiency in legumes is very low $0.03-5.1 \%$ (Yan et al. 2000, Senthil et al. 2004). Using PPT as a selectable marker Nadolska-Orczyk and Orczyk (2000) got the transformation efficiency of $1.47 \%$, Grant et al. (1998) got the transformation efficiency of $3.6 \%$ in pea transformation. Khatib et al. (2007) got the transformation efficiency of 0.01 to $0.43 \%$ in case lentil transformation.

Shoots that survived on $2.0 \mathrm{mg} / \mathrm{PPT}$ were separated and transferred to half strength of MS supplemented with $20 \mathrm{mg} / \mathrm{IBA}$ and $0.5 \mathrm{mg} / \mathrm{NAA}$. After 2 - 3 weeks in vitro flower formation was observed (Fig. 2C) on the healthy shoots. From this experiment it was found that 11 out of 26 survived shoots responded to flowering and the maximum number of flower per shoot was 3. It was also found that after $15-20$ days of flowering 3 out of these 11 flowering shoots produced viable and healthy pods (Fig. 2D) under in vitro condition and the range of pods per shoot was $1-2$. Results of these experiments are presented in Table 2.

Pods that developed on $T_{0}$ shoots were harvested, dried under sunlight and were subjected for germination in plastic pot containing sterile peat moss in nethouse along with controls (non-transformed). The $\mathrm{T}_{0}$ seeds germinated and gave rise to $\mathrm{T}_{1}$ plants (Fig. $2 \mathrm{E}$ ) as well as the $\mathrm{T}_{1}$ seeds germinated and gave rise to $\mathrm{T}_{2}$ plants (Fig. $2 \mathrm{~F}$ ). The non- 
transformed controls were used to compare the growth and were the source for negative control. It was found that branching in $T_{n}(n=$ number of denoting progeny) was comparatively low, resulting in less leaf material. Otherwise no significant differences were noticed.

Table 2. Response of transformed shoots towards in vitro flowering and pod formation.

\begin{tabular}{lcccccc}
\hline Variety & $\begin{array}{c}\text { No. of shoots } \\
\text { transferred to } \\
\text { flowering media }\end{array}$ & $\begin{array}{c}\text { No. of shoots } \\
\text { respond to } \\
\text { flowering }\end{array}$ & $\begin{array}{c}\text { \% of shoots } \\
\text { respond to } \\
\text { flowering }\end{array}$ & $\begin{array}{c}\text { No. of flowers/ } \\
\text { shoot } \\
\text { (Mean } \pm \text { Sd) }\end{array}$ & $\begin{array}{c}\text { No. of shoots } \\
\text { responded to } \\
\text { pod formation }\end{array}$ & $\begin{array}{c}\text { No. of pods/ } \\
\text { shoot } \\
\text { (mean } \pm \text { Sd) }\end{array}$ \\
\hline $\mathrm{BM}-4$ & 7 & 1 & 14.29 & $1.0 \pm 0$ & 0 & 0 \\
$\mathrm{BM}-5$ & 7 & 3 & 42.86 & $1.33 \pm 0.58$ & 1 & $1.0 \pm 0$ \\
$\mathrm{BM}-6$ & 12 & 7 & 58.33 & $1.57 \pm 0.79$ & 2 & $1.0 \pm 0$ \\
\hline
\end{tabular}
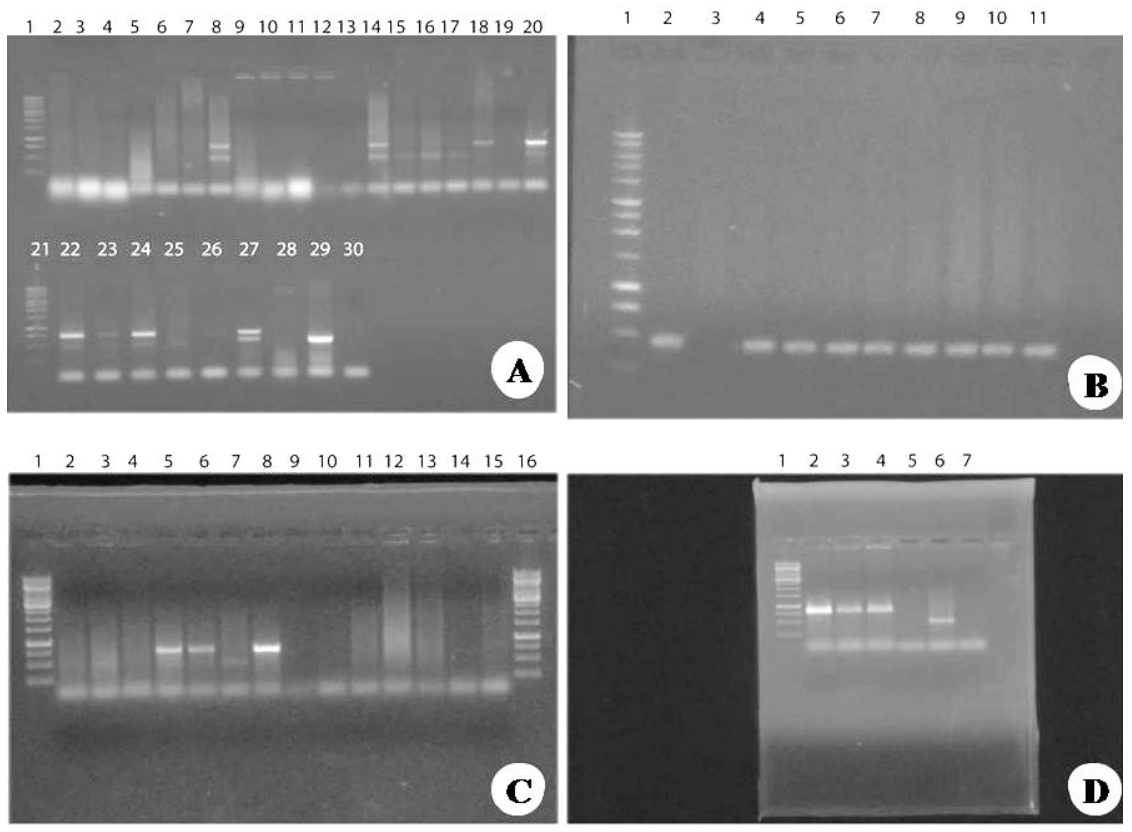

Fig. 3. PCR amplification of chitinase and bar gene of putative transformants. A. PCR amplification of chitinase gene from To plants of lentil. Note that, lanes $8,14,18,20,22,23,24$ and 27 produced corresponding band, identical to the band obtained from positive control (lane 30). Lane 2, 3, 4, 5, 6, 7, 9, 10, 11, 12, 13, 15, 16, 17, 19,25 and 26 are non transformed plantlets. Lane 1 refers for $1 \mathrm{~kb}$ ladder, lane 28 negative control, lane 29 positive control and lane 30 for water control. B. Same as fig. A in case of bar gene (lane 1 for $1 \mathrm{~kb}$ ladder, lane 2 positive control, lane 3 negative control, lane 4 - 11 putative transformants and lane 12 water control). C. PCR amplification of chitinase gene from $\mathrm{T}_{1}$ plants of lentil. Note that, lanes 5 and 6 comes from lane 24 of $T_{0}$ plants produced corresponding band, identical to the band obtained from positive control (lane 8); no signal from negative control (lane 11), water control (lane 10) and non transformed plants (lane 2, 3, 4, 7 and 9). D. same as Fig. $C$ in case of $T_{2}$ plants, note that lane 3 and 4 come from lane 5 of $\mathrm{T}_{1}$ plant produced corresponding band, identical to the band obtained from positive control ( lane 2); no signal from negative control ( lane 6) and water control (lane 5). 
Transgenic nature of the putative transformed was confirmed through PCR analysis. Shoots that recovered (7 [lane 2-8] from BM-4, 7 [lane 9-15] from BM-5 and 12 [lane 16 27] from BM-6) through selection pressure was subjected for PCR analysis. Among them 8 (1 [lane 8] from BM-4, 1 [lane 14] from BM-5 and 6 [lane 18, 20, 22, 23, 24, 27] from BM6) survived shoots showed positive response towards the integration of bar and chitinase genes. The presence of amplified band at $0.46 \mathrm{~kb}$ for bar gene and $0.55 \mathrm{~kb}$ for chitinase gene in transformed shoots confirmed the presence of bar and chitinase gene (Fig. 3A, B). DNA isolation and PCR amplification for chitinase gene was also done from the $\mathrm{T}_{1}$ and $\mathrm{T}_{2}$ plants (Fig. 3C, D).

From this experiment it was observed that in some cases although the $\mathrm{T}_{0}$ clones were positive with bar gene but some of them turned out negative in the PCR of chitinase gene. This could be the result of incomplete T-DNA transfer as the transfer initiated from right border got aborted before reaching the left border. It is well known that T-DNA transfer to plant cells occurs in a defined direction, starting from the right to the left border (Becker et al. 1992, Zambyski 1992). Hassan (2006) reported similar phenomenon in the study of pea transformation.

From the foregoing discussion, it may be concluded that using this protocol it has been possible to develop transgenic plantlets using antifungal genes in other plants with various explants types. Available literature indicated that this may be the pioneering report on the successful development of transgenic microsperma group of lentil plants. However, the frequency of transformation was rather low which needs to be addressed in the future work of lentil genetic transformation.

\section{Acknowledgment}

This investigation was supported by the US Department of Agriculture (USDA) through a project entitled "Improvement of grain legumes through transformation".

\section{References}

Bakr MA (1994) Checklist of pulse diseases in Bangladesh. Bangladesh Journal of Plant Pathol. 10(1 and 2): 13- 16.

Barton JE, Klyne A, Tennakoon D, Francis C and Hamblin J (1997) Development of a system for gene transfer to lentils. In: International food Legume Research Conference III, Adelaide, 85.

Becker D, Kamper E, Schell J and Masterson R (1992) New plant binary vectors with selectable markers located proximal to the left T-DNA border. Plant Molecular Biol. 20: 1195-1197.

Celikkol UA, Mahmoudian M, Kamci H, Yucel M and Oktem HA (2009) Agrobacterium tumefacien-mediated genetic transformation of a recalcitrant grain legume, lentil (Lens culinaris Medik). Plant Cell Rep. 28: 407-417. 
Das SK, Shethi KJ, Hoque MI and Sarker RH (2012) Agrobacterium mediated genetic transformation in lentil (Lens culinaris Medik.) followed by in vitro flowering and seed formation. Plant Tissue Cult \& Biotechnol. 22(1): 13 -26.

Doyle JJ and Doyle JL (1990) Isolation of plant DNA from fresh tissue. Focus 12: 13-15.

Erskine W (1984) Evaluation and utilization of lentil germplasm in an international breeding program. In: Witcombe, J.R., Erskine, W., eds. Genetic resources and their exploitation chickpeas, faba and lentils. The Hague: Martinus Nijhoff; 225-237.

Grant JE, Cooper PA, Gilpin BJ, Hoglund SJ, Reader JK, Pither-Joyce MD and TimmermanVaughan GM (1998) Kanamycin is effective for selecting transformed peas. Plant Sci. 139: 159164.

Gulati A and McHughen H (2003) In vitro regeneration and genetic transformation of lentil. Applied Genetics of Leguminosae Biotechnology, pp. 133-147.

Halbach T, Kiesecker H, Jacobsen HJ and DeKathen A (1998) Tissue culture and genetic engineering of lentil (Lens culinaris Medik.) In: $3^{\text {rd }}$ European Conference on Grain Legumes, Valladolid. 376.

Hassan F (2006) Heterologous expression of a recombinant chitinase from Streptomyces olivaceoviridis ATCC 11238 in transgenic pea (Pisum sativum L.). Ph.D. thesis, Hannover University, Germany.

Hellens RP, A Edwards, NR Leyland, S Bean and Mullineaux PM (2000) pGreen: A versatile and flexible binary Ti vector for Agrobacterium-mediated plant transformation. Plant Mol. Biol. 42: 819-832.

Hood EE, Gelvin SB, Melchers LS and Hoekema A (1993) New Agrobacterium helper plasmids for gene transfer to plants.Transgenic Res. 2: 208-218.

Khatib F, Koudsieh S, Ghazal B, Batron JE, Tsjimoto H and Baum M (2007) Developing herbicide resistant lentil (Lens culinaris Medikus subsp. culinaris) through Agrobacterium-mediated transformation. Arab J. Pl. Prot. 25(2): 187-192.

Krishnamurthy KV, Suhasini K, Sagare AP, Meixner M, De Kathen A, Pickardt T and Schieder O (2000) Agrobacterium-mediated genetic transformation of chickpea (Cicer arietinum L.) embryo axes. Plant Cell Rep. 19: 235-240.

Mansur EA, Lacorte C, DeFreitus VG, DeOlivierea DE, Timmerman B and Cordeiro AR (1993) Regulation of transformation efficiency of peanut (Arachis hypogea L.) explants by Agrobacterium tumefaciens. Plant Sci. 89: 93-99.

Nadolska-Orczyk A and Orczyk W (2000) Study of the factors influencing Agrobacterium mediated transformation of pea (Pisum sativum L.) Mol Breed. 6: 185-194.

Sarker RH, Mustafa BM, Biswas A, Mahbub S and Hoque MI (2003) Agrobacterium-mediated transformation of lentil (Lens culinaris Medik.). Plant Tissue Cult. 13(1): 1-12.

Senthil G, Williamson B, Dinkins RD and Ramsay G (2004) An efficient transformation system for chickpea (Cicer arientum L.). Plant Cell Rep. 23: 297-303.

Warkentin TD and McHughen A (1991) Crown gall formation of lentil (Lens culinaris Medik.) with virulent strains of Agrobacterium tumefaciens. Plant Cell Rep. 10: 489-493.

Warkentin TD and McHughen A (1992) Agrobacterium tumefaciens-mediated beta-glucoronidase (GUS) gene expression in lentil (Lens culinaris Medik.) tissues. Plant Cell Rep. 11: 274-278. 
Warkentin TD and McHughen A (1993) Regeneration from lentil cotyledonary nodes and potential of this explant for transformation by Agrobacterium tumefaciens. Lens Newsletter 20(1): 26-28.

Wiese WB, Vorman E and Krause HK (1994) Structural organization and differential expression of three stilbene synthase genes located on a $13 \mathrm{~kb}$ grapevine DNA fragment. Plant Mol. Biol. 26: 667-677.

Williams PC, Bhatty RS, Deshpande SS, Hussein LA and Savage GP (1994) Improving nutritional quality of cool season food legumes. In: Expanding the production and use of cool season food legumes (Eds. Muehlbauer, F.J. and Kaiser, W.J.) Kluwer, Academic Publishers, Dordrecht, The Nethetlands, 113-129.

Yan B, Srinivasa Reddy MS, Collins GB and Dinkins RD (2000) Agrobacterium tumefaciens mediated transformation of soyabean [Glycine max (L.) Merrill.] using immature zygotic cotyledon explants. Plant Cell Rep. 19: 1090-1097.

Zambyski PC (1992) Chronicles from the Agrobacterium-plant cell DNA transfer story. Annu Rev Plant Physiol. Mol. Biol. 43: 4645-4690.

(Manuscript received on 20 May, 2019; revised on28 May, 2019) 